Exposure to threatening and violent behaviour among single mothers the significance of lifestyle, neighbourhood and welfare situation

Felipe Estrada

Anders Nilsson

Department of Criminology

Stockholm University

S-10691 Stockholm

Sweden

Accepted for publication in The British Journal of Criminology (030115) 


\section{Exposure to threatening and violent behaviour among single mothers - the significance of lifestyle, neighbourhood and welfare situation ${ }^{1}$}

The objective of this article is to study violent victimisation among single mothers. This is mainly achieved by examining variations within the group of single mothers. The study is based on the Annual Survey of Living Conditions conducted by Statistics Sweden. The analysis includes a total of 1,713 single mothers. One of the central issues in this study is to examine the significance of factors related to participation in public entertainment, residential neighbourhood and resource deficiencies at the individual level. One important conclusion from the study is that differences in levels of exposure to violence, both within the group of single mothers and between this group and other women, are primarily related to levels of individual welfare resources.

\section{Introduction}

Surveys asking people about their levels of exposure to crime have consistently shown single mothers to suffer particularly high levels of victimisation by comparison with other social groups. This has led to family type coming to be regarded as an important risk factor in relation to criminal victimisation (see for example Hindelang, Gottfredson \& Garofalo 1978:15; Maxfield 1987; Mawby \& Walklate 1994:51f). In an earlier study of changes in levels of victimisation linked to the Swedish economic crisis of the 1990s (Nilsson \& Estrada 2003), we showed that in addition to this disproportionate risk for victimisation, there is also a tendency towards polarisation in victimisation levels; whilst the majority of the Swedish population present stable levels of exposure to violent crime, levels of victimisation among weaker socio-economic groupings, including single mothers, have increased. This gives rise to the question of how these higher levels of victimisation among single mothers are to be explained. From a welfare-political point of view, the question is an interesting one in that criminal victimisation may in many ways be regarded as a problem of welfare (Nilsson \& Estrada 2003). On the basis of the perspective employed in the Swedish 'level-of-living'

\footnotetext{
${ }^{1}$ Contact with authors; Department of Criminology (www.crim.su.se), Stockholm University, S-106 91 Stockholm, Sweden. The authors would like to thank David Shannon for his translation of the text.
} 
surveys, variations in levels of exposure to or fear of crime across different social groups may be interpreted in terms of welfare differences, and an increase in levels of victimisation may be seen as an indicator of increasing welfare problems.

A closer study of the high levels of victimisation experienced by single mothers is also interesting from a theoretical point of view. Two explanatory models dominate the criminological research literature in this area. The one tradition proceeds first and foremost from the importance of individual and situational factors. Here attention is focused on the individual's lifestyle (Hindelang et al 1978) and routine activities (Cohen \& Felson 1979). These so-called opportunity theories explain variations in levels of criminal victimisation between different demographic groups (as defined by age, sex, family type and income, for example) as the result of differences in the activity patterns of these groups. Variations in lifestyle/routine activities involve variations in levels of exposure to situations involving a risk for exposure to crime. According to the lifestyle model, exposure to crime is linked to the role expectations of the group to which an individual belongs (Hindelang et al 1978:242f). Thus young people's relatively high levels of involvement in nightlife explain their high levels of exposure to violence by comparison with those reported by groups of more advanced years, for example. The lower levels of victimisation experienced by married women by comparison with single mothers is regarded as being linked to activity patterns which see married women spending a large proportion of their time in the home and thus more seldom being exposed to risk situations (ibid.:249). Consequently, opportunity theorists have assumed the higher levels of risk experienced by single mothers to be dependant on their being forced into full time work to a greater extent and on the fact that their status as singles involves relatively high levels of participation in nightlife. These assumptions have met with a considerable amount of criticism, however, not least because a significant amount of the violence perpetrated against single mothers takes place in the home (Maxfield 1987).

A further problem for the lifestyle model is that the variations across different demographic groups may to some extent be spurious. Exposure to violence may be the result of structural factors that determine where and how different groups live their lives, rather than on activity patterns that result from choices made at the individual level. Advocates of the model have also noted the significance of these factors: "Among the important consequences of family income are where one lives, how one lives, and with whom one comes into contact. Poor people have little choice about these matters; if the situation is undesirable in any respect, 
those in poverty have little choice but to cope." (Hindelang et al 1978:262) It is therefore somewhat surprising that victim surveys based on the lifestyle perspective have consistently failed to focus an adequate amount of attention on the socio-economic conditions in which individuals live their lives (Smith \& Jarjoura 1989; Meier \& Miethe 1993).

The socio-economic structural conditions that affect people's lives are given a more central position within the other dominant explanatory model, however, based on social disorganisation theory. Here, the risk of exposure to crime is viewed as a function of the levels of crime and other social problems present in an individual's residential environment. These will depend on the levels of formal and informal social control in a given residential neighbourhood, which are in turn related to the area's socio-economic structure (Shaw \& McKay 1942). The theory emphasises the relative importance of neighbourhood characteristics over individual factors (Smith \& Jarjoura 1989; Sampson \& Lauritsen 1990; Wikström 1998). Average household income in a given neighbourhood is regarded as more important than the individual's level of income, for example (Smith \& Jarjoura 1989). A weak financial situation indicates that people live in less attractive residential neighbourhoods, which are in turn more likely to be characterised by higher levels of social problems, leading to relatively high levels of victimisation risk (ibid.; Sampson \& Lauritsen 1990; Dolmén 2002).

The lifestyle and social disorganisation perspectives dominate the field in relation to the explanation of criminal victimisation at the general level. There are a number of other perspectives, however. Central to efforts to understand the violent victimisation of women are perspectives that take account of the prevailing gender order and power relations: "If, within the wider social setting, men have more power over women, then there is more likely to be male violence over women at moments when partners disagree, than in settings where this power is more equal" (Walby 2002:22). Whilst recognition of the role played by patriarchal social structures is essential to an understanding of men's violence against women, it is nonetheless important to look at the question of the more immediate situations in which such violence occurs. A key element in research of this kind is the use of a comparative method, i.e. comparing the circumstances where violence occurs and where it does not. The question of what it is that makes women vulnerable has received only a limited amount of attention by comparison with the amount of research that has focused on the male perpetrators of such violence (Gelles 1998:194; Kaufman Kantor \& Jasinski 1998:14f; Walby 2002). 
Given that power relations are seen as playing an important role in relation to exposure to crime, individuals' living standards and the resources available to them to affect their own lives will also play a part. The Scandinavian level-of-living surveys proceed from a perspective which views individual resources and circumstances as determining the opportunities available to a given individual. Individuals' levels of living and welfare situations are in fact defined as these individuals' levels of access to and control over resources that enable them, in the context of existing conditions, consciously to exercise control over their lives. One of the important principles underlying this definition is that it views the individual as an active being, capable of making her own decisions if she is given the resources to do so. A sound financial situation constitutes a central welfare-related resource, but both Scandinavian and international welfare research has emphasised the importance of studying individuals' levels of living and welfare situation along a number of different dimensions. The Swedish Annual Survey of Living Conditions (ULF) therefore focuses on the measurement of individuals' level of well-being in very broad terms. In addition to questions on the respondents' financial situation, the interviewers ask a string of questions on a variety of issues relating to levels of well-being, including health, housing, social relations, education and employment. Together, these various factors are deemed to determine the level of opportunities available to an individual to affect his or her life situation (Sen 1985; Erikson 1993; Palme et al 2002). The focus of the surveys is on identifying those who lack resources, rather than those living the good life.

It is unusual for victim surveys to study the link between various dimensions of welfare and exposure to crime. This constitutes something of a flaw given that welfare research has found clear evidence that different aspects of welfare are related (see for example Erikson 1993; Palme et al 2002). The fact that those who lack resources in one area often also experience shortfalls in other areas serves to exacerbate differences in levels of welfare between different individuals and groups. Differences in levels of accumulated welfare problems may be regarded as an indicator both of the opportunities available to an individual and of levels of social exclusion (Nilsson 2002). Studying the link between accumulations of welfare problems and exposure to crime thus becomes a means of approaching the question of social exclusion and its significance for criminal victimisation. 


\section{Objectives and research questions}

Earlier analyses of exposure to crime have for the most part limited themselves to identifying and comparing the situation of different demographic groupings, inter alia examining variations across individuals presenting different family structures, such as single persons and cohabitees. An analysis focusing on within-group variations, comparing the social conditions of those exposed to violence and those not experiencing this form of victimisation, would provide an important opportunity to examine the question of which factors make some more vulnerable than others. An analysis of this kind should differentiate between risk factors related to socio-economic situation, and those associated with the activity patterns of different demographic groups.

The objective of this article is to analyse single mothers' exposure to violence. The presentation begins by describing the different forms of violence experienced by this group. Three fundamental dimensions of this violence are examined - its seriousness, its frequency and where it takes place. Levels of victimisation among single mothers are then compared to those of women and men respectively within the population at large. Following the presentation of this comparison, the focus shifts to variations within the group of single mothers. The factors examined include a lifestyle involving frequent participation in 'public entertainments' such as visits to bars, pubs, cinemas and so forth, residential neighbourhood effects and the role of the welfare situation. A low level of within-group variation may be interpreted as an indication that the high levels of victimisation experienced by single mothers may be explained in terms of the lifestyle associated with membership of this particular demographic group. Clear, patterned differences in levels of victimisation among single mothers, on the other hand, would lead to a shift in the explanatory focus away from family type per se, and towards the specific conditions associated with a heightened risk for exposure to violence.

The principle research questions addressed by the study are thus as follows:

- How common is violent victimisation among single mothers? How does this group differ from the population at large as regards the proportion victimised and the types of violence experienced?

- What differences exist in relation to exposure to violence within the group of single mothers? What role is played in these differences by a person's lifestyle, residential area and welfare situation respectively? 


\section{The data}

The following description and analysis of experiences of victimisation is based on the Annual Survey of Living Conditions (ULF) conducted by Statistics Sweden. The surveys employ structured home interviews with representative samples from the Swedish population aged between sixteen and eighty-four years. Each year, interviews are conducted with approximately 6,000 people. The attrition rate lies at around twenty per cent. For the purposes of this study, we have had access to the surveys conducted between 1988 and 1999. These surveys comprise data collected in a total of 72,017 interviews.

We have limited the analysis to an examination of persons of working age, i.e. those aged between eighteen and sixty-four years, which gives a sample comprising 55,327 individuals. The category 'single mothers' comprises those who answered at interview that they were single with a youngest child of no more than seventeen years of age. Slightly over one-third (37\%) of the single mothers have a youngest child of pre-school age (0-6 years). The analysis includes a total of 1,713 single mothers, with a mean age of 37.5 years. The first stage of the analysis involves comparing the victimisation of these single mothers with that experienced by other women and by men. We are well aware that the comparison groups differ from the study group in relation to several factors besides just gender and family type. ${ }^{2}$ Our primary focus is directed at within-group variations, however, and we have therefore chosen not to standardise the data further for the purposes of this preliminary comparison.

As regards to experiences of violence, the ULF surveys include four key questions relating to differing degrees of violence. The first refers to the most serious forms of violence and reads: During the last twelve months, have you personally been the victim of a violent act or acts that have lead to injuries requiring you to visit a doctor, dentist or nurse? The respondent is then asked about violence which caused visible marks or physical injury, violence that did not lead to visible marks or physical injury and whether he or she has been threatened with violence in such a way as to be frightened. If a person has been exposed to one or more of these forms of violence, the interviewer asks on how many occasions this has been the case. The respondents are also asked where these incidents have taken place, distinguishing

\footnotetext{
${ }^{2}$ The age composition of the groups differs, for example, despite our having restricted the population to those aged eighteen to sixty-four; the single mothers constitute a somewhat younger and more homogenous group
} 
between six principle alternatives (see Table 1). It should be noted that the ULF-survey does not constitute a traditional crime survey in which respondents are required to decide whether they have been the victim of a crime (see Walby \& Myhill 2001 for a critical examination of crime surveys). Here the survey's focus is on measuring the living conditions of citizens, and questions relating to exposure to threatening behaviour and violence are included as one component among many intended to measure a broad conception of welfare.

The victim surveys of the kind included in the ULF studies are subject to certain well-known limitations. The principle problems include attrition levels, difficulties relating to the study of serious criminal offences, and over- and under-reporting. Respondents may find questions relating to experiences of violence difficult to deal with. This is particularly true of questions relating to domestic violence and sexual offences (Mawby \& Walklate 1994; Walby \& Myhill 2001). A further problem is that those groups that are known to be at particularly high risk of exposure to crime - e.g. the homeless, people with a criminal record, and drug and alcohol abusers - are less well represented than others in these surveys (Nilsson 2002; see also Lambert \& Wiebel 1990). This ought not to effect the general picture of the experiences of victimisation of the population as a whole, however, because these groups are relatively small.

\section{Exposure to threats and violence among single mothers and others}

Table 1 compares the proportion of single mothers reporting exposure to different forms of threatening behaviour and violence with the corresponding proportion among women and men within the remainder of the population. The table distinguishes between three dimensions of violence; the seriousness of the violence, the frequency of the violence, and the place where the violence occurred. As expected, the results show that single mothers do constitute a high risk group. The differences in relation to other women tend to be greater the more serious the form of violence, with the proportion of single mothers reporting exposure to violence requiring medical treatment being five times the size of this proportion among other women. Repeat victimisation constitutes a further criterion for judging the seriousness of violence (Carlstedt 2001). Other men and women who have experienced violence over the course of the previous twelve months most often report this having happened on only a single occasion 
during that time. The single mothers reporting such experiences, however, most commonly report having been subject to violence repeatedly. As was the case in relation to the degree of seriousness, the excess risk among single mothers is greater the higher the number of violent incidents.

It is clear from Table 1 that violence taking place in the home plays an important role in producing the differences between the groups examined, a finding that has previously been reported on the basis of British data (Maxfield 1987). It is seven times as common for single mothers to have experienced violence of this kind than it is for other women. Violence in the home relates to a large extent to incidents where the perpetrator is a man with whom the woman has been involved in a close relationship (SCB 1995:95f). It should therefore be noted that it is more difficult for women living together with partners to report incidents of violence in the home perpetrated by these partners (Walby \& Myhill 2001). This means that the findings relating to the comparison between single mothers and other women may to some extent represent an overestimation of the actual differences between these groups. Table 1 also shows, however, that single mothers present higher levels of exposure to other forms of violence too. The exceptions to this general rule are violence in the workplace, which is the most common form of violence experienced by other women, and violence on public transport. These findings should be regarded as providing confirmation of the fact that single mothers are exposed to substantially higher levels of violence and that this cannot simply be the result of differences in the reporting behaviour of the different groups compared, since the differences in levels of exposure are substantial and are not restricted to violence that takes place in the home. 
Table 1. Proportion (per cent) exposed to threats and violence during the previous twelve months. 1864 year-olds. ULF 1988-1999

\begin{tabular}{|c|c|c|c|}
\hline & $\begin{array}{l}\text { Single mothers } \\
(n=1713)\end{array}$ & $\begin{array}{l}\text { Other women } \\
\text { 18-64 years } \\
(n=25943)\end{array}$ & $\begin{array}{l}\text { Men } \\
18-64 \text { years } \\
(n=27670)\end{array}$ \\
\hline \multicolumn{4}{|l|}{ Seriousness } \\
\hline Threats or violence of any kind & 15,6 & 5,9 & 8,5 \\
\hline Threatening behaviour & 11,6 & 4,0 & 4,7 \\
\hline No visible injury & 4,2 & 1,3 & 2,2 \\
\hline Visible injury & 4,6 & 1,3 & 2,1 \\
\hline Medical treatment required & 2,1 & 0,5 & 1,2 \\
\hline \multicolumn{4}{|l|}{ Repeat victimisation } \\
\hline No experience of threats or violence & 84,5 & 94,2 & 91,5 \\
\hline Exposed to threats or violence once & 5,7 & 2,8 & 4,5 \\
\hline $2-4$ times & 4,4 & 1,7 & 2,6 \\
\hline 5-10 times & 2,0 & 0,6 & 0,7 \\
\hline More than 10 times & 3,3 & 0,7 & 0,8 \\
\hline \multicolumn{4}{|l|}{ Type of violence } \\
\hline Own dwelling & 8,4 & 1,2 & 0,7 \\
\hline Other dwelling & 1,6 & 0,3 & 0,4 \\
\hline Workplace & $3,0 \mathrm{~ns}$ & 2,6 & 1,9 \\
\hline Street or other public place & 2,8 & 1,4 & 3,4 \\
\hline Bar, club or other place of entertainment & 1,2 & 0,5 & 2,3 \\
\hline Public transport - train, bus, station & $0,2 \mathrm{~ns}$ & 0,3 & 0,6 \\
\hline Other place & 1,3 & 0,4 & 0,6 \\
\hline
\end{tabular}

The difference between single mothers and other women (aged 18-64) is significant ( $p<0.001, x^{2}$-test) unless stated otherwise (ns).

There are clear differences between single mothers and other women in levels of exposure to violence associated with public entertainments. At the same time, it is clear from Table 1 that this category of violence is of relatively little significance for the differences in exposure to violence that exist between these two groups of women. This finding suggests that even at this early stage of the analysis, the explanatory value of one of the factors most commonly cited in lifestyle model explanations may be assumed to be rather limited (see also Maxfield 1987; Rodgers \& Roberts 1995). Instead the absolute differences are greater in relation to violence that takes place in the street or other public places. This finding could certainly be interpreted as providing support for an explanatory model based on the routine activities approach, provided single mothers spend more of their time out of doors in relatively high risk environments. The problem with this interpretation, as is pointed out by Meier \& Miethe (1993), is that the same finding could fit equally well with an explanation based on social disorganisation theory, i.e. that there is a neighbourhood effect reflecting the fact that single 
mothers tend to live in areas characterised by a higher risk for exposure to crime. In order to shed a little more light on the suitability of these different explanatory models, we now shift the focus of the analysis to look exclusively at the group of single mothers.

\section{Differences between single mothers who have been exposed to violence and} those who have not

By examining which single mothers are at particularly high risk of exposure to violence, it becomes possible to develop an idea of the factors that are responsible for the excessive victimisation risk experienced by single mothers as a group. To begin with, bivariate correlations are examined between background factors, involvement in public entertainments, area of residence and welfare situation on the one hand and exposure to threatening or violent behaviour in various locations on the other (cf. Table 1). Following this descriptive analysis, we move on to the use of multivariate analyses in order to study the effects of different risk factors in more detail.

\section{Demographic background conditions and public entertainment}

One of the most fundamental assumptions of the lifestyle model is that variations in how often individuals go out, and in particular go out to enjoy themselves in the evening, is directly reflected in differences in levels of victimisation (Hindelang et al 1978:251). For this reason, one of the most common operationalisations employed when studying the lifestyle model is to divide respondents into groups on the basis of how often they go out to restaurants, bars, pubs, dance clubs, the cinema and so forth (see for example Hindelang et al 1978; Maxfield 1987; Meier \& Miethe 1993;). Several studies have shown that such a relationship does exist at the general level. At the same time, the same studies have sometimes found that this effect is not particularly substantial in relation to the analysis of repeat violent victimisation or indeed for any kind of violent victimisation once controls are included for the respondents' age (Miethe, Stafford \& Long 1987; van Kesteren, Mayhew \& Nieuwbeerta 2000; Carlstedt 2001; Dolmén 2002).

In the present study involvement in public entertainment is measured on the basis of questions asking how often a respondent has gone to the cinema or to a restaurant, pub or cafe in order to enjoy themselves. ${ }^{3}$ Those who have been classified in the group who "rarely go out"

\footnotetext{
${ }^{3}$ These questions were not posed in the years 1992-1995. The number of respondents is therefore 1,115 (cf.
} 
answered that they participate in one of these activities approximately once every three months at most. Those who answered that they participate in one of these activities approximately once a month have been classified in the group that "go out occasionally". Those classified as "go out often" answered that they participate in both activities once a month or more, or that they participate in at least one of the activities on a weekly basis.

As regards background variables the findings presented in Table 2 show that country of birth is of limited significance. Single mothers born abroad and those born in Sweden differ in only two regards; firstly, the proportion of those born abroad who were exposed to violence in the street was twice as large as this proportion among those born in Sweden; secondly, a somewhat larger proportion of those born abroad had been exposed to threatening or violent behaviour on more than one occasion. The differences between sub-groups of single mothers are greater when these groups are formed on the basis of the respondents' age. Younger single mothers report substantially higher levels of victimisation than their older counterparts. There are also clear differences between groups formed on the basis of the age of the youngest child. ${ }^{4}$ None of the three background variables had any effect in relation to violence in the workplace.

Table 2 shows further that levels of exposure to violence among single mothers cannot be explained by reference to how often they go out to enjoy themselves. Very few single mothers report that they often go out to enjoy themselves. This is not surprising given the financial constraints this group lives under (Gähler 1998 and below) and the need to make childcare arrangements. Further, few single mothers are exposed to violence at places of public entertainment. Nor is there a link between being a single mother and being exposed to violence perpetrated on the street.

Table 1). Of these, 85 did not respond to the questions on how often they go to various places of public entertainment.

${ }^{4}$ The significance of the number of children has been examined, but does not affect the results. 
Table 2. Proportion (per cent) of single mothers exposed to different types of threatening and violent behaviour over the past twelve months, by demographic background characteristics and participation in public entertainment. ULF 1988-1999

\begin{tabular}{llllllll}
\hline & $\begin{array}{l}\text { Threats } \\
\text { or } \\
\text { violence }\end{array}$ & Work & Home & $\begin{array}{l}\text { Bar, pub } \\
\text { etc. }\end{array}$ & Street & $\begin{array}{l}\text { Repeatedly }_{\text {victimised }}^{5} \\
\text { N }\end{array}$ \\
\hline $\begin{array}{l}\text { Background } \\
\text { characteristics }\end{array}$ & & & & & & & \\
$\begin{array}{l}\text { Country of birth } \\
\text { - Sweden }\end{array}$ & 15,0 & 3,2 & 8,9 & 1,3 & 2,5 & 7,6 & 1411 \\
- Other country & 19,0 & 2,0 & 12,0 & 0,7 & 5,0 & 11,3 & 300 \\
Age & $* * *$ & & $* * *$ & $* * *$ & $* * *$ & $* * *$ & \\
- Young (18-29 years) & 27,2 & 3,8 & 17,2 & 4,1 & 5,9 & 15,9 & 320 \\
- Older (30 +) & 13,0 & 2,8 & 7,6 & 0,6 & 2,1 & 6,5 & 1391 \\
Age of youngest child & $* * *$ & & $* * *$ & $* *$ & & $* * *$ & \\
- 0-6 years & 23,0 & 3,6 & 15,0 & 2,1 & 3,9 & 12,9 & 665 \\
- 7-18 years & 11,0 & 2,6 & 5,8 & 0,7 & 2,3 & 5,3 & 1046 \\
Participation in public & & & & & & & \\
entertainment & & & & & & & 547 \\
Rarely goes out & 15,2 & 1,8 & 9,9 & 1,1 & 3,3 & 8,0 & 391 \\
Goes out sometimes & 14,1 & 2,8 & 7,9 & 1,5 & 3,3 & 6,6 & 9,6 \\
Goes out often & 14,1 & 5,4 & 7,6 & 2,2 & 1,1 & 7,6 & \\
\hline
\end{tabular}

$* \mathrm{p}<.05, * * \mathrm{p}<.01, * * * \mathrm{p}<.001$

\section{Residential neighbourhood}

As has been mentioned above, the residential neighbourhood constitutes the central factor for explanations based on social disorganisation theory. Using aggregate area level data, several studies have confirmed the existence of neighbourhood effects on criminal victimisation when individual factors are controlled for (see e.g. Smith \& Jarjoura 1989; Sampson \& Lauritsen 1990; Rountree, Land \& Miethe 1994). On the whole, however, studies that work with data at both the individual and neighbourhood level remain rare, often as a result of a lack of good data at the neighbourhood level (Dolmén 2002). Unfortunately, this study has not had access to data relating to specific residential neighbourhoods. We have therefore been forced to adopt an indirect approach to the question of the neighbourhood's significance.

The findings from research based on the theory of social disorganisation often show the following four fundamental characteristics of neighbourhoods to be related to increases in the risk for exposure to crime at the individual level (Wikström 1998:270f; Dolmén 2002); the

\footnotetext{
${ }^{5}$ The term 'repeatedly victimised' refers to respondents who report having been exposed to non-work-related
} 
neighbourhoods are in larger cities rather than in smaller towns or rural areas, the housing stock is dominated by blocks of flats/apartment buildings rather than single-family houses, of rented accommodation rather than owner-occupied homes, and the neighbourhoods are characterised by a relatively high rather than a relatively low level of problems. These particular living conditions are examined in Table 3. The level of problems in a given neighbourhood is measured using the question "Are acts of vandalism or other forms of damage a common occurrence in the public spaces, play areas, parks and so forth found in this residential neighbourhood?" Those answering that it is quite common or very common were judged to live in a neighbourhood with a high level of problems. In line with the basic tenets of social disorganisation theory, the various indicators of neighbourhood living conditions were combined in order to distinguish those living in areas that may be assumed to involve an increased risk for violent victimisation. Thus a composite variable was formed on the basis of these various indicators which enabled high risk neighbourhoods (i.e. those fulfilling the above four criteria) to be distinguished from others on the basis of the interview responses. When interpreting the findings, it should be remembered that since we are proceeding from the individual as the unit of analysis, i.e. employing the form of home in which the individual lives rather than actual neighbourhood characteristics, we are unable to produce a direct measure of neighbourhood effects.

Of the various conditions presented in Table 3, tenancy form is that most closely related to violent victimisation. The levels of victimisation presented by single mothers who live in cities or metropolitan areas are no higher than those of single mothers living in rural areas. The presence of vandalism in the neighbourhood appears to be only weakly correlated with levels of exposure to threatening or violent behaviour. Looking at the composite neighbourhood variable we find that those living in high risk neighbourhoods do experience higher levels of violent victimisation than others; approximately one quarter of those living in high risk neighbourhoods have been exposed to threatening or violent behaviour over the course of the previous year, as against around one in seven of those not living in such areas. An examination of the different categories of violence shows that living in a high risk area only involves a significantly higher risk for victimisation in relation to violence in the home.

\footnotetext{
threats or violence on more than one occasion over the course of the previous twelve months.

${ }^{6}$ The question on vandalism was not included in the years 1988 and 1989. The number of respondents is therefore 1457. One of the possible answers (namely 'no opinion on the matter') has not been included in the table (75 individuals gave this answer). These are included amongst those who do not perceive there to be problems on the composite neighbourhood variable.
} 
Table 3. Proportion (per cent) of single mothers exposed to different types of threatening or violent behaviour during the past twelve months, by residential neighbourhood. ULF 1988-1999.

\begin{tabular}{|c|c|c|c|c|c|c|c|}
\hline & $\begin{array}{l}\text { Threats / } \\
\text { violence }\end{array}$ & Work & Home & $\begin{array}{l}\text { Bar, pub } \\
\text { etc. }\end{array}$ & Street & $\begin{array}{l}\text { Repeat } \\
\text { victim }\end{array}$ & $\mathbf{N}$ \\
\hline \multicolumn{8}{|l|}{$\begin{array}{l}\text { Residential neighbourhood } \\
\text { Region }\end{array}$} \\
\hline City or metropolitan area & 16,1 & 3,3 & 9,3 & 1,1 & 3,3 & 8,7 & 1275 \\
\hline Rural area & 14,4 & 2,1 & 9,6 & 1,6 & 1,8 & 6,9 & 436 \\
\hline Type of building & $* *$ & & $*$ & $*$ & & $* *$ & \\
\hline Block of flats/apartments & 17,5 & 3,1 & 10,6 & 1,7 & 3,1 & 9,5 & 1144 \\
\hline Single-family housing & 11,9 & 2,7 & 6,9 & 0,4 & 2,7 & 5,5 & 563 \\
\hline Tenancy form & $* * *$ & & $* * *$ & $* *$ & & $* * *$ & \\
\hline Rent paying & 17,8 & 2,6 & 11,0 & 1,8 & 3,3 & 10,0 & 1122 \\
\hline Owner occupier & 11,4 & 3,7 & 6,1 & 0,2 & 2,2 & 4,8 & 587 \\
\hline Vandalism in area & $*$ & & & & & & \\
\hline Yes & 20,6 & 2,2 & 12,5 & 0,6 & 3,7 & 10,6 & 321 \\
\hline No & 15,3 & 3,4 & 8,9 & 1,4 & 2,9 & 8,0 & 1057 \\
\hline $\begin{array}{l}\text { Composite neighbourhood } \\
\text { variable }\end{array}$ & $* *$ & & $*$ & & & & \\
\hline High risk neighbourhood & 23,9 & 2,3 & 13,6 & 0,5 & 4,2 & 13,7 & 213 \\
\hline Other & 15,3 & 3,2 & 9,2 & 1,4 & 2,8 & 9,9 & 1242 \\
\hline
\end{tabular}

$* \mathrm{p}<.05, * * \mathrm{p}<.01, * * * \mathrm{p}<.001$

\section{Welfare conditions}

Both the lifestyle model and social disorganisation theory view financial conditions as playing a significant role in variations in levels of criminal victimisation. At the individual level, victim surveys commonly show low income groups to present the highest levels of violent victimisation (see e.g. Mawby \& Walklate 1994:46; Kaufman Kantor \& Jasinski 1998:27; Nilsson \& Estrada 2003). A number of surveys, including the International Crime Victims Survey (van Kesteren, Mayhew \& Nieuwbeerta 2000:54ff) ${ }^{7}$ and national studies focused particularly on violence against women (Lundgren et al 2002), have failed to find such a correlation, however. On the basis of studies of this latter kind, the Council of Europe have published a report on domestic violence stating that: "It should be stressed, that poverty and lack of education are not significant factors. It is even proved that the incidence of domestic violence seems to increase with income and the level of education." (Council of Europe

\footnotetext{
${ }^{7}$ For a number of reasons, it is difficult to know how to treat the findings from this study, however. The analysis is conducted simultaneously for 17 different countries, which differ in relation to levels of victimisation, socioeconomic conditions and levels of attrition. Further, the method chosen by Van Kasteren et al (2000:55), of differentiating between low-income and high-income households simply by dividing into two groups at the average also differs from the method employed in other studies which often include a more substantial amount of variance between low-income and high-income households (e.g. Nilsson \& Estrada 2003).
} 
2002:9) ${ }^{8}$ This conclusion is somewhat remarkable given the findings produced by other research in this area (for a survey of previous research see for example Mawby \& Walklate 1994:46; Kaufman Kantor \& Jasinski 1998:25f; Engström 1999).

The financial situation is examined below on the basis of two sources of data. The first consists in the respondent's answer to a direct question as to whether she had experienced difficulties keeping up with recurrent expenses for food, rent, bills etc. over the course of the preceding year. ${ }^{9}$ The other consists in register data indicating whether the respondent had been in receipt of income support payments from the social services during the previous twelve months. Health is studied by asking the respondents to themselves assess their general state of health, a method which is regarded as providing a very good measure of health levels within the population at large (Fritzell \& Lundberg 2000:97). Where respondents have reported that their state of health is not good, the present study has categorised them into an 'ill-health' group. The group with limited education includes those with no education to speak of beyond their final year of compulsory schooling. The group referred to as employed includes, besides those in traditional forms of full- or part-time work, those who are selfemployed, on maternity leave and students. Social relations and social support have been measured using the question Do you have a very close friend whom you can get in touch with and talk to about anything at all? (Not counting members of your family or others in your household). Differences in cumulative numbers of problems across different welfare dimensions may be regarded as an indicator of both the level of opportunities available to an individual and of his or her level of social exclusion (Nilsson 2002). Accordingly, we have summed across the welfare indicators described above to produce an additive index of accumulated welfare problems or resource deficiencies at the individual level. ${ }^{10}$

\footnotetext{
${ }^{8}$ Studies of this type tend to use a considerably wider definition of violence. For one thing, they tend to look at whether individuals have ever been exposed to violence, rather than exposure to violence over the course of the preceding year. In addition, their operationalisations of violence include a variety of types of incidents of widely disparate degrees of seriousness. One important merit of such studies is that they are better able to identify sexspecific types of violence such as sexual violence and sexual harassment (Johnson \& Sacco 1995; Lundgren et al 2002). For a discussion of the consequences of methodological factors for the study of violence against women see also Lenton (1995) and Walby \& Myhill (2001).

${ }^{9}$ This question was not included in the 1999 survey. The number of respondents is therefore 1,568.

${ }^{10}$ The index of welfare problems includes the components: health, education, social relations and self-reported financial situation. These indicators are of established use within the field of Swedish welfare research (see for example Palme et al 2002). Since the question relating to financial difficulties was not included in the 1999 survey, those reporting that they lacked a 'cash safety margin' were counted as having had financial difficulties for that year. Lacking a cash safety margin refers to those respondents who reported that they would be unable to find a given amount of money if an unforeseen situation arose requiring them to do so within a week (the sum in question amounted to approximately 1,500 Euro in the 1999 survey. Previous studies have shown these two questions to overlap to a high degree (Nilsson \& Estrada 2003).
} 
Table 4 makes it clear that exposure to threatening and violent behaviour is associated with other welfare related factors. Of those who report ill-health, a limited education, unemployment, financial difficulties or not having a close friend, between one-fifth and onequarter report having been exposed to threats or violence during the previous twelve months. Among the other respondents, levels of victimisation lie at between ten and fifteen per cent. The greatest differences are to be found in relation to violence in the home and repeat victimisation, where risk levels are two to three times as high among those reporting one of the welfare related problems. Looking instead at the individual welfare components, those who do not have a close friend to talk to are twice as likely to be exposed to violence in the home or to be victimised repeatedly. This combination is indicative of a particularly vulnerable situation. The welfare resources most closely linked to exposure to threats or violence are financial difficulties (income support) and unemployment. It is also clear that differences in relation to these welfare components have no effect on single mothers' exposure to work-related violence.

When we shift the focus to look at the number of problems accumulated at the individual level, the correlation between welfare related resources and victimisation becomes even clearer. With the exception of violence at the workplace, the proportion reporting victimisation increases across all types of violence with each incremental increase in the cumulative number of problems. The one-third of respondents who lack welfare related problems of any of the kinds examined here are significantly less exposed to violence than those reporting problems in one or more areas. One in ten of those with no welfare-related problems have been exposed to threatening or violent behaviour and three per cent report having been victimised on more than one occasion. Among those with welfare related problems in four or more areas, four of ten have experience of threats or violence over the course of the previous twelve months and almost one-third have been victimised on more than one occasion. 
Table 4. Proportion (per cent) of single mothers exposed to various types of threatening or violent behaviour during the past twelve months, by a number of welfare indicators. ULF 1988-1999

\begin{tabular}{|c|c|c|c|c|c|c|c|}
\hline & $\begin{array}{l}\text { Threats/ } \\
\text { violence }\end{array}$ & Work & Home & $\begin{array}{l}\text { Bar, pub, } \\
\text { etc. }\end{array}$ & Street & $\begin{array}{l}\text { Repeat } \\
\text { victim }\end{array}$ & $\mathbf{N}$ \\
\hline $\begin{array}{l}\text { Components of welfare } \\
\text { Health }\end{array}$ & $* * *$ & & $* * *$ & & $* * *$ & $* * *$ & \\
\hline $\begin{array}{l}\text { - Ill-health (self-assessed) } \\
\text { - Good health }\end{array}$ & $\begin{array}{l}24,0 \\
12,5\end{array}$ & $\begin{array}{l}1,7 \\
3,5\end{array}$ & $\begin{array}{l}14,6 \\
7,5\end{array}$ & $\begin{array}{l}1,7 \\
1,0\end{array}$ & $\begin{array}{l}5,6 \\
1,9\end{array}$ & $\begin{array}{l}14,8 \\
5,8\end{array}$ & $\begin{array}{l}466 \\
1245\end{array}$ \\
\hline $\begin{array}{l}\text { Education } \\
\text { - Compulsory only } \\
\text { - 1-2 years further ed. } \\
\text { - } 3+\text { years further ed. }\end{array}$ & $\begin{array}{l}* * * \\
21,7 \\
16,5 \\
11,5\end{array}$ & $\begin{array}{l}1,8 \\
3,7 \\
2,7\end{array}$ & $\begin{array}{l}* * \\
13,9 \\
9,4 \\
7,0\end{array}$ & $\begin{array}{l}* * \\
2,4 \\
1,6 \\
0,2\end{array}$ & $\begin{array}{l}4,8 \\
2,8 \\
2,1\end{array}$ & $\begin{array}{l}* * * \\
14,2 \\
8,0 \\
5,4\end{array}$ & $\begin{array}{l}332 \\
752 \\
627\end{array}$ \\
\hline $\begin{array}{l}\text { Employment } \\
\text { - Unemployed } \\
\text { - Employed }\end{array}$ & $\begin{array}{l}* * * \\
25,0 \\
14,0\end{array}$ & - & $\begin{array}{l}* * * \\
16,2 \\
8,1\end{array}$ & $\begin{array}{l}* * * \\
3,4 \\
0,8\end{array}$ & $\begin{array}{l}* * * \\
7,5 \\
2,1\end{array}$ & $\begin{array}{l}* * * \\
15,9 \\
6,8\end{array}$ & $\begin{array}{l}264 \\
1447\end{array}$ \\
\hline $\begin{array}{l}\text { Social relations } \\
\text { - No close friend } \\
\text { - Has close friend }\end{array}$ & $\begin{array}{l}* \\
23,0 \\
15,0\end{array}$ & $\begin{array}{l}1,4 \\
3,1\end{array}$ & $\begin{array}{l}* \\
15,1 \\
8,9\end{array}$ & $\begin{array}{l}1,4 \\
1,2\end{array}$ & $\begin{array}{l}3,6 \\
2,9\end{array}$ & $\begin{array}{l}* * * \\
15,8 \\
7,6\end{array}$ & $\begin{array}{l}139 \\
1571\end{array}$ \\
\hline $\begin{array}{l}\text { Self-reported financial } \\
\text { situation } \\
\text { - Experienced financial } \\
\text { difficulties } \\
\text { - No financial difficulties }\end{array}$ & $\begin{array}{l}* * * \\
20,6 \\
10,0\end{array}$ & $\begin{array}{l}2,4 \\
3,4\end{array}$ & $\begin{array}{l}* * * \\
14,1 \\
4,7\end{array}$ & $\begin{array}{l}1,6 \\
0,8\end{array}$ & $\begin{array}{l}* \\
3,5 \\
1,7\end{array}$ & $\begin{array}{l}* * * \\
12,3 \\
4,3\end{array}$ & $\begin{array}{l}795 \\
767\end{array}$ \\
\hline $\begin{array}{l}\text { Registered financial } \\
\text { situation }\end{array}$ & $* * *$ & & $* * *$ & $* *$ & $* * *$ & $* * *$ & \\
\hline $\begin{array}{l}\text { - Received income support } \\
\text { - Not received income } \\
\text { support }\end{array}$ & $\begin{array}{l}28,6 \\
10,7\end{array}$ & $\begin{array}{l}1,7 \\
3,3\end{array}$ & $\begin{array}{l}20,5 \\
5,5\end{array}$ & $\begin{array}{l}2,7 \\
0,7\end{array}$ & $\begin{array}{l}4,8 \\
1,8\end{array}$ & $\begin{array}{l}18,4 \\
4,8\end{array}$ & $\begin{array}{l}413 \\
1154\end{array}$ \\
\hline Resource deficiency & $* * *$ & $*$ & $* * *$ & $*$ & $* * *$ & $* * *$ & \\
\hline - No welfare problems & 9,1 & 4,4 & 4,0 & 0,2 & 1,2 & 2,9 & 519 \\
\hline - One problem & 12,7 & 3,4 & 7,1 & 1,3 & 1,6 & 6,1 & 621 \\
\hline - Two problems & 20,0 & 1,4 & 13,7 & 1,7 & 5,1 & 11,7 & 350 \\
\hline - Three problems & 29,1 & 0,0 & 20,9 & 2,0 & 6,1 & 16,9 & 148 \\
\hline - Four/five problems & 39,7 & 2,7 & 23,3 & 4,1 & 9,6 & 30,1 & 73 \\
\hline
\end{tabular}

$* \mathrm{p}<.05, * * \mathrm{p}<.01, * * * \mathrm{p}<.001$

\section{Risk factors underlying single mothers' exposure to violence; a more detailed} analysis

In order to examine the risk factors related to violent victimisation more closely, logistic regression analyses (Menard 1995) have been employed. Analyses of this kind calculate the likelihood that a certain event will occur, which allows for the likelihood, or risk, for exposure to crime to be calculated and compared across different groups. The results are presented as odds ratios for the various independent variables, expressed below as deviations from a reference category that is ascribed the value 1 . The odds ratios do not specify the size of the 
effects of the various independent variables. Rather, these ratios quantify the difference in likelihood across different categories of an independent variable when the remaining independents included in the model are held constant. An odds ratio greater than one involves a higher risk in relation to the reference category on a given variable, whilst an odds ratio of less than one indicates a lower risk. ${ }^{11}$

The first stage (Models A and B) tests the importance of demographic background factors and levels of participation in public entertainment. In Model A, only the three background characteristics are included: country of birth, age and age of youngest child. In Model B, the public entertainments variable is added. This part of the analysis is based on the 1,030 respondents who were questioned as to how often they go out to enjoy themselves. In stage two (Models C-E), the importance of welfare related factors and residential neighbourhood are examined. Models C-E are based on 1,455 respondents. The respondents not included in this stage of the analysis are missing as a result of the fact that the questions on vandalism in the respondents' residential neighbourhood were not included every year. The background factors are also included in model C. In model D, the indicators of welfare related problems in the areas of health, education, social relations, employment and the respondent's financial situation are included in the form of the additive welfare problem index presented above (Table 2). The use of the index is preferred to the inclusion of the individual indicator variables, since the various welfare problems have been shown to be related to one another, and since the earlier comparisons have shown that it is the cumulative number of problems that is of primary importance. Finally, in model E, residential neighbourhood effects are also included.

\footnotetext{
${ }^{11}$ The models have been constructed blockwise, with tests being conducted to establish whether the addition of further independent variables produces a significant improvement in the model's ability to 'predict' the outcome of the various dependant variables. The comparison involved here is based on a test of the change in -2 loglikelihood (-2 LL), which stated simply provides a measure of how much the model fails to explain. Whether or not the additional variables have led to a significant improvement in the model can be read from row entitled 'model improvement' in the following tables.
} 
Table 5. Single mothers' exposure to threatening or violent behaviour during the previous twelve months. Relative differences (odds ratios) by background factors, lifestyle, welfare situation and residential neighbourhood. ULF 1988-1999.

\begin{tabular}{|c|c|c|c|c|c|}
\hline & \multicolumn{5}{|c|}{ Threatening or violent behaviour } \\
\hline & \multicolumn{2}{|l|}{ Stage 1} & \multicolumn{3}{|l|}{ Stage 2} \\
\hline & $\mathrm{A}$ & $\mathrm{B}$ & $\mathrm{C}$ & $\mathrm{D}$ & $\mathrm{E}$ \\
\hline $\begin{array}{l}\text { Background factors } \\
\text { Country of birth }\end{array}$ & & & & & \\
\hline Born in Sweden & 1 & 1 & 1 & 1 & 1 \\
\hline Born abroad & $1,74 *$ & $1,70 *$ & $1,45^{*}$ & 1,08 & 1,05 \\
\hline Age & & & & & \\
\hline Young (18-29 years) & $1,96^{* *} *$ & $1,99 * *$ & $1,66^{* *}$ & $1,78^{*}$ & 1,45 \\
\hline $\operatorname{Older}(30+)$ & 1 & 1 & 1 & 1 & 1 \\
\hline Age of youngest child & & & & & \\
\hline Pre-school & $2,40 * * *$ & $2,41 * * *$ & $1,99 * * *$ & $1,89 * * *$ & $1,91 * * *$ \\
\hline School age & 1 & 1 & 1 & 1 & 1 \\
\hline $\begin{array}{l}\text { Participation in public } \\
\text { entertainment }^{12}\end{array}$ & & Ns & & & \\
\hline Rarely & & 1 & & & \\
\hline Sometimes & & 0,88 & & & \\
\hline Often & & 0,85 & & & \\
\hline Areas of resource deficiency ${ }^{13}$ & & & & $\mathrm{P}<.001$ & $\mathrm{P}<.001$ \\
\hline 0 & & & & 1 & 1 \\
\hline 1 & & & & $1,58 *$ & $1,56^{*}$ \\
\hline 2 & & & & $2,63 * * *$ & $2,55 * * *$ \\
\hline 3 & & & & $3,88 * * *$ & $3,77 * * *$ \\
\hline $4-5$ & & & & $7,60 * * *$ & $7,28 * * *$ \\
\hline Residential neighbourhood & & & & & \\
\hline High risk & & & & & 1,41 \\
\hline Other & & & & & 1 \\
\hline$-2 \mathrm{LL}$ & 804,328 & 803,800 & 1256,244 & 1198,485 & 1195,330 \\
\hline Model chi-square & 54,216 & 54,745 & 50,050 & 107,808 & 110,964 \\
\hline Model improvement & & Ns & & $\mathrm{p}<.001$ & $\mathrm{p}<.05$ \\
\hline $\mathrm{N}$ & 1030 & 1030 & 1455 & 1455 & 1455 \\
\hline
\end{tabular}

The results from the first stage of the analysis (Models A and B in Table 5) show that the three background factors are all related to differences in exposure to threatening or violent behaviour. The single mothers who are born abroad, those who are younger and in particular those with children of pre-school age, are at higher risk of victimisation. On the other hand, as

\footnotetext{
${ }^{12}$ This public entertainments variable has no effect even if age is excluded from the model (see also Table 2). The variable has no effect when it is included in models D and E.

${ }^{13}$ The five variables included in this index (health, education, financial situation, employment and social relations) are all significantly related to one another (gamma $0,14-0,56 ; \mathrm{p}<0.05$ ).
} 
was also found in the analysis of simple correlations presented earlier, there is no significant association between participation in various forms of public entertainment and exposure to violence. In stage two (Models C-E) we see that levels of welfare problems are clearly related to the risk for exposure to threatening or violent behaviour, even when controls are included for the effects of background factors. This is the variable that produces the greatest differences. The pattern is clear; the greater the resource deficiency, the greater the risk of exposure to threats or violence. Once controls are included for a lack of welfare related resources in this way, the effect of country of birth disappears; i.e. when individuals are divided into homogenous groups by sex, age group, family type and levels of welfare related problems, there are no differences in violent victimisation within these groups between those born in Sweden and those born abroad. Finally, Model E sees the inclusion of the residential neighbourhood indicator. Neighbourhood has no effect on victimisation when background factors and resource deficiencies at the individual level are held constant. Thus the findings indicate that the differences in victimisation related to residency patterns are dependant on something other than neighbourhood effects. ${ }^{14}$

In order to further illuminate the significance of the various risk factors, we have chosen to split the dependant variable by type (location) of violence and frequency; this is done in order to examine whether the risk factors presented above have a varying effect on different forms of violence. Table 6 shows that resource deficiencies at the individual level involve an increased risk for exposure to violence at home, on the street and in places of public entertainment as well as for repeat victimisation. Once again, residential neighbourhood has no significant effect. The age of the youngest child is linked to an excess risk for exposure to violence in the home and for repeat victimisation, two phenomena which overlap one another to a large extent.

\footnotetext{
${ }^{14}$ The same results were obtained using an additive index variable relating to the residential neighbourhood (level of urbanisation, tenancy form, type of housing, and vandalism). The variable had no significant effect on levels of exposure to threatening or violent behaviour when controls were included for individual background factors and welfare conditions.
} 
Table 6. Exposure to threatening or violent behaviour during the previous twelve months among single mothers, by location of victimisation and repeat victimisation. Relative differences (odds ratios) by welfare-related problems and residential neighbourhood. The models include controls for age and country of birth. ULF 1988-1999, $(n=1,456){ }^{15}$

\begin{tabular}{llll}
\hline & Home & Street/bar etc. & Repeat victim \\
\hline $\begin{array}{l}\text { Background factors } \\
\text { Age of youngest child }\end{array}$ & & & \\
$\begin{array}{l}\text { Pre-school } \\
\text { School age }\end{array}$ & $2,33 * * *$ & 0,85 & $1,82^{* *}$ \\
& 1 & 1 & 1 \\
Areas of resource deficiency ${ }^{16}$ & & & \\
0 & 1 & 1 & 1 \\
1 & $2,02 *$ & 1,93 & $2,20^{*}$ \\
2 & $4,27 * * *$ & $4,38^{* *}$ & $4,60^{* * *}$ \\
$3-5$ & $6,80^{* * *}$ & $6,64 * * *$ & $8,37^{* * *}$ \\
& & & \\
Residential neighbourhood & & & 1,25 \\
High risk & 1,21 & 0,90 & 1 \\
Other & 1 & 1 & \\
$* * * * \mathrm{p}<0.001 ; * *$ & $\mathrm{p}<0.01 ; *=\mathrm{p}<0.05$ & &
\end{tabular}

The findings thus far have shown that the neighbourhood in which a single mother resides has no effect on the likelihood of exposure to violence when controls are included for welfare related resource deficiencies at the individual level. The question remains nonetheless as to whether the welfare deficiencies might combine with residency in a high-risk neighbourhood to generate particularly high levels of risk for victimisation. A model (table not presented) which included the welfare index and residential neighbourhood factors as an interaction term did not however improve the fit or 'explanatory power' of the model. What was shown, however, was that the risk of victimisation is very high in the group where an accumulation of resource deficiencies at the individual level are combined with residence in a high-risk neighbourhood. This can also be seen from Table 7, which shows that it is primarily the individuals' welfare-related problems that answer for the differences in levels of victimisation. As was shown earlier, we can see that the proportion of those reporting victimisation increases with the number of accumulated welfare problems, irrespective of the situation in the respondent's residential neighbourhood. The only significant neighbourhood

\footnotetext{
${ }^{15}$ The public entertainment variable has no effect on any of the various types of violence. We have chosen not to include this variable in the final models since doing so would have involved a substantial reduction in the number of observations (cf. Table 4).

${ }^{16}$ We have chosen to combine the categories 3-5 (instead of 4-5, see Table 4) since fewer individuals are exposed to each of the various types of violence than are exposed to all forms of threatening or violent behaviour. This enables us to avoid problems associated with individual observations assuming a disproportionate weight in the analyses. In concrete terms, the levels of excess risk associated with the highest
} 
effects are found among those reporting the highest levels of accumulated welfare problems, of whom approximately half of those living in high-risk neighbourhoods report exposure to threatening or violent behaviour over the course of the previous year as compared with 30 per cent of those living in non high-risk neighbourhoods. Here we see a tendency towards what has been termed "structural amplification", whereby the combination of personal disadvantage and community disadvantage is associated with a particularly high risk for criminal victimisation (Ross, Mirowski \& Pribesh 2001). This further underscores the link between social exclusion and exposure to violence.

Table 7. Proportion (per cent) of single mothers exposed to threatening or violent behaviour over the previous twelve months, by welfare-related problems and residential neighbourhood $(n=1,455)$.

\begin{tabular}{|c|c|c|}
\hline \multirow[t]{2}{*}{ Areas of individual resource deficiency } & \multicolumn{2}{|c|}{ Type of residential neighbourhood } \\
\hline & $\operatorname{High}$ risk (n) & Other $(n)$ \\
\hline 0 & $(41)$ & $8,6 \quad(397)$ \\
\hline 1 & 19,7 & $12,6 \quad(451)$ \\
\hline 2 & $20,7 \quad(58)$ & $22,1 \quad(244)$ \\
\hline $3-5$ & $51,2 * *(43)$ & $30,0 \quad(150)$ \\
\hline
\end{tabular}

\section{Discussion and conclusions}

The objective of this article has been to study violent victimisation among single mothers. The article's chief focus has been directed at examining variations within the group of single mothers. Studying which factors are related to an excessive risk for exposure to violence and which factors are not, illuminates the question of what it is that makes certain people more vulnerable than others. One of the central issues in this study has been to examine the significance of factors related to participation in public entertainment, residential neighbourhood and resource deficiencies at the individual level.

The findings provide further confirmation for previous research which has shown single mothers to constitute a highly vulnerable group. Differences in relation to the remainder of the population were particularly large with regard to violence in the home and repeat victimisation. The study has also found a high level of clearly patterned variation within the 
group of single mothers itself. The major differences found to exist between those who do and do not have welfare related problems makes it sensible to treat single mothers as comprising two distinct groups. In relation to levels of exposure to threatening and violent behaviour, single mothers from the group with no welfare related problems are more similar to the remainder of the population than they are to single mothers who are experiencing a number of such problems. The large proportion of those presenting the highest levels of resource deficiency who have also experienced threats and violence over the course of the previous year indicates that these women occupy a highly marginalised social position where violent victimisation is not an isolated problem.

If we look to the theoretical models that are at present dominant within the field of criminology, i.e. the lifestyle and social disorganisation perspectives, the findings from the current study provide no support for either. There are clear problems for the lifestyle model as a result of the extensive within-group variance in exposure to violence that is in turn associated with welfare related conditions at the individual level; those presenting the greatest resource deficiencies present substantially higher levels of victimisation than others. The lifestyle perspective's most serious flaw is quite simply that it tends to focus attention on the wrong questions; exposure to violence is not related to the possible role expectations associated with being a single mother (cf. Hindelang et al 1978:242f). Nor can the withingroup variance be explained by reference to differences in levels of participation in public entertainment. The one element of the lifestyle model that does look promising is the understanding that poor financial resources lead to limitations in the level of available opportunities (ibid: 262), a factor which has up to now received little attention within this theoretical tradition, however. Our findings provide further evidence that the lifestyle model does not work as a general theory, but is rather gender and context bound; the violence it explains best is that perpetrated by males against other males in public places. If we are to understand the violence perpetrated against women, it is essential to go further and look to the wider social context in which the risk for victimisation is particularly great (see also Dobash \& Dobash 1995; Rodgers \& Roberts 1995).

Social disorganisation theory is also faced with problems as a result of the fact that neighbourhood factors have no decisive impact on the victimisation of single mothers. The major problem for an explanatory model focused on neighbourhood factors is that much of the violence in question affects under-resourced or marginalised women in the home. Thus 
the women who live in high-risk neighbourhoods but who do not present resource deficiencies do not report similarly high levels of victimisation, something which they ought to do if neighbourhood characteristics were more important than individual factors (cf. Smith \& Jarjoura 1989). What our findings instead show is that the welfare related situation of single mothers, and thus the opportunities available to them to affect their own living conditions, are related to their victimisation risk. All of the welfare problems examined here - ill-health, limited education, unemployment, poor financial resources and a lack of social relations involve substantial increases in the risk for exposure to violence. This becomes even clearer when we focus on the cumulative number of welfare related problems; the more the areas in which an individual lacks resources, the greater the level of victimisation.

It is important to make the point that the resource deficiencies identified as risk factors in this study do not immediately suggest themselves as causal factors. In order to understand women's exposure to violence it is of course important to focus attention on the perpetrator, which also constitutes the most common approach when examining this question. The literature often refers to social and psychological problems as a contributory causal factor (Gelles 1998; Kaufman Kantor \& Jasinski 1998). Perspectives that focus on the prevailing power structure and gender order are also central in this context, as was mentioned earlier. Although recognising the role of patriarchal social structures is essential to an understanding of men's violence against women, it is nonetheless important to look at the question of the more immediate situations in which such violence occurs (Gelles 1998:194; Walby 2002). What our findings clearly show is that there are social situations which involve a particularly high risk for victimisation. We have been able to show that exposure to violence tends to be one welfare related problem among many, which makes the situation of these victims particularly serious. In the light of these findings, the contention that social and economic factors are of no significance, as has been maintained by amongst others the Council of Europe (Council of Europe 2002:9), is difficult to understand. What such an interpretation fails to take note of is that besides the patriarchal power structure, there are other power relations, positions of subordination and limitations on the ability to affect one's own situation, that are central to any understanding of women's exposure to violence.

We view the limitations placed on individuals' ability to affect their own lives that result from resource deficiencies as a central mechanism behind the link between welfare related problems and exposure to violence. Limited resources, greater social isolation and thus 
reduced access to informal and formal support networks make it more difficult to deal with or escape a situation of vulnerability (see also Walby 2002). The vast majority of single mothers have gone through a separation; this may in itself constitute a risk factor since such separations are often grounded in some form of conflict. With the addition of the stress associated with financial problems, the likelihood of conflict is further increased (Lenton 1995:307f; Kaufman Kantor \& Jasinski 1998:25f). The concept “marital dependency” has been employed in relation to cohabiting women with children as a means of describing the relationship between the opportunities available to them and domestic violence; their lack of resources makes it more difficult for them to leave a partner who threatens and/or assaults them (Walby 2002). This mechanism is relevant to the situation of single mothers too. For those with young children, who lack social support, have a poor financial situation, and so forth, it is easy to see that this dependency (via maintenance payments, for example) is maintained, along with regular contacts, and with them possible conflict situations. This could constitute one explanation for the high levels of victimisation experienced by those with young children and deficient resources.

The question of the mechanisms involved remains to a large extent unanswered, however, and the data employed in the current study are subject to clear limitations in this regard. One important conclusion that may nonetheless safely be drawn from this study is that differences in levels of exposure to violence, both within the group of single mothers and between this group and other women, are related to levels of welfare resources (see also Nilsson \& Estrada 2003). Measures aimed at improving the situation of single mothers, besides producing the self-evident welfare dividends involved when the opportunities available to a large group of individuals are extended, also have the potential to decrease levels of violent victimisation. 


\section{References}

Carlstedt, M. (2001), Upprepad viktimisering. En studie av utsatthet för brott i Sverige

(Repeat Victimization. A study of victimization in Sweden). Department of Criminology, Stockholm University.

Cohen, L. \& Felson, M. 1979. "Social Change and Crime Rate Trends", $\underline{\text { American }}$ Sociological Review, 44:588-608.

Council of Europe (2002), Domestic Violence. Doc. 9525. Report. Committee on Equal Opportunities for Women and Men. Parliamentary Assembly. Council of Europe.

Dobash, R.P. \& Dobash, R.E. (1995), “ Reflections on findings from the Violence Against Women Survey", Canadian Journal of Criminology, 37:457-484.

Dolmén, L. (2002), Brottslighetens geografi. En analys av brottsligheten i Stockholms län (The Ecology of Crime. An analysis of crime in Stockholm). Doctoral dissertation. Stockholm: Department of Criminology.

Engström, K. (1999), Social Inequality in Violence Related Injuries. Knowledge accumulated, research needs, and alternatives for prevention. Stockholm: National Institute of Public Health.

Erikson,. R. (1993), “Descriptions of Inequality: the Swedish approach to welfare research”, in M. Nussbaum \& A. Sen, eds., The Quality of Life, 67-83. Oxford: Oxford University Press.

Fritzell, J. \& Lundberg, O. (2000), Välfärd, ofärd och ojämlikhet (Welfare, Disadvantage and Inequality). Swedish Government Official Report (SOU) 2000: 41. Stockholm: Fritzes.

Gelles, R.J. (1998), "Family Violence”, in M. Tonry (ed), The Handbook of Crime and Punishment. Oxford: Oxford University press.

Gähler, M. (1998), Life after Divorce. Economic, social and psychological well-being among Swedish adults and children following family dissolution. Doctoral dissertation. Stockholm: Swedish Institute for Social Research.

Hindelang, M., Gottfredson, M. \& Garofalo, J. (1978), Victims of Personal Crime: An empirical foundation for a theory of personal victimization. Cambridge: Ballinger.

Johnson, H. \& Sacco, V.F. (1995), “Researching violence against women: Statistics Canada's national survey", Canadian Journal of Criminology, 37:281-304.

Kaufman Kantor G. \& Jasinski, J.L. (1998), "Dynamics and Risk Factors in Partner Violence” in J.L. Jasinski \& L.M. Williams (ed), Partner Violence. A comprehensive review of 20 years of research. London:Sage. 
van Kesteren, J., Mayhew, P. \& Nieuwbeerta, P. (2000), Criminal Victimisation in Seventeen Industrialised Countries. The Hague: WODC.

Lambert, E.Y. \& Wiebel, W. (1990), The Collection and Interpretation of Data from Hidden Populations. Institute on Drug Abuse, Research monograph series 98: U.S. Department of health and human services.

Lenton, R.L. (1995), "Power versus feminist theories of wife abuse", Canadian Journal of Criminology, 37:305-330.

Lundgren, E., Heimer, G. Westerstrand, J. \& Kalliokoski, A.M. (2002), Captured Queen: men's violence against women in "equal" Sweden : a prevalence study, Stockholm : Fritzes.

Mawby, R. \& Walklate, S. (1994), Critical Victimology. London: Sage.

Maxfield, M. G. (1987), “Household Composition, Routine Activity and Victimization: A Comparative Analysis". Journal of Quantitative Criminology, 3:301-320.

Meier, R. F. \& Miethe, T. D. (1993), “Understanding Theories of Criminal Victimization”, in M. Tonry (ed), Crime and Justice. A Review of Research, 17:459-497.

Miethe, T. D., Stafford, M. C. \& Long, S. J. (1987), "Social Differences in Criminal Victimization: A Test of Routine Activities/Lifestyle Theories”. American Sociological Review, 52:184-194.

Menard, S. (1995), Applied Logistic Regression Analysis. London: Sage.

Nilsson, A. (2002), Fånge i marginalen - uppväxtvillkor, levnadsförhållanden och återfall $i$ brott bland fangar. (Confined to the margins. The childhood, living conditions and recidivism of prison inmates), Doctoral dissertation. Stockholm: Department of Criminology.

Nilsson, A. \& Estrada, F. (2003), "Victimisation, Inequality and Welfare during an Economic Recession. A Study of Self Reported Victimisation in Sweden 1988-1999." British Journal of Criminology. Accepted for publication.

Palme, J., Bergmark, Å., Bäckman, O., Estrada, F., Fritzell, J., Lundberg, O. \& Szebehely, M (2002), “Welfare Trends in Sweden. Balancing the Books for the 1990's”. Journal of European Social Policy, 12:329-346.

Rodgers, K. \& Roberts, G. (1995), “Women's non-spousal multiple victimization: A test of the routine activities theory", Canadian Journal of Criminology, 37:363-391.

Ross, C., Mirowski, J \& Pribesh, S. (2001), "Powerlessness and the amplification of threat: Neighbourhood disadvantage, disorder, and mistrust". American Sociological Review, 66:568-591. 
Rountree, P.W., Land, K.C. \& Miethe, T.D. (1994), "Study of Victimization: A hierarchical logistic model analysis across Seattle neighbourhoods"” Criminology, 32:387-414.

Sampson, R. J. \& Lauritsen, J. L. (1990), “Deviant Lifestyles, Proximity to Crime, and the Offender-Victim link in Personal Violence". Journal of Research in Crime \& Delinquency, 27:110-140.

SCB (1995), Offer för Vålds- och Egendomsbrott 1978-1993. (Victims of Violence and Property Crimes) Report 88, Stockholm: Statistics Sweden.

Sen, A. (1985), Commodities and Capabilities. Amsterdam: North Holland.

Shaw, C.R. \& McKay, H.D. (1942), Juvenile Delinquency and Urban Areas. Chicago: The University of Chicago Press.

Smith, D.A. \& Jarjoura, R.G. 1989. "Household Characteristics, Neighborhood Composition and Victimization Risk", Social Forces, 68:621-640.

Walby, S. \& Myhill, A. (2001), ”New Survey Methodologies in Researching Violence Against Women." British Journal of Criminology, 41:502-522.

Walby, S. (2002), "Reducing Gendered Violence: Defining, measuring and interpreting interpersonal violence and responses to it”. In M. Eriksson, A. Nenoloa \& M. Muhonen Nielsen (ed.), Gender and Violence in the Nordic Countries. Report from a conference in Koge, Denmark, 23-24 november 2001. Copenhagen: Nordisk ministerråd.

Wikström, P.O. (1998), “Communities and Crime”, in M. Tonry (ed), The Handbook of Crime and Punishment, 269-301. Oxford: Oxford University press. 